\title{
Augmentation of AUSGeoid98 with GRACE satellite gravity data
}

\author{
W E Featherstone \\ Western Australian Centre for Geodesy \& The Institute for Geoscience Research, \\ Curtin University of Technology, GPO Box U1987, Perth, WA 6845, Australia \\ W.Featherstone@curtin.edu.au
}

\begin{abstract}
The AUSGeoid98 gravimetric quasigeoid model of Australia is augmented in the medium- and long-wavelength bands by removing its EGM96 basis and replacing this with GGM02C and EIGEN-GL04C, whose long wavelengths are derived from Gravity Recovery And Climate Experiment (GRACE) satellite gravimetry. No significant improvement over AUSGeoid98 is seen: agreements with GPS-levelling change from \pm 28 $\mathrm{cm}$ to $\pm 27 \mathrm{~cm}$ (acknowledging distortions in the levelling); agreements with astrogeodetic vertical deflections do not change, remaining at about \pm 1 arc-second. While this remove-replace approach is not theoretically exact, it is likely that errors in the terrestrial gravity data are contaminating these combined GRACE solutions in the medium wavelengths over Australia.
\end{abstract}

Keywords: Geodesy, quasigeoid modelling, GRACE, GPS-levelling, vertical deflections, Australia

\section{INTRODUCTION}

The majority of the long- and medium-wavelength components of the AUSGeoid98 gravimetric quasigeoid model of Australia (Featherstone et al., 2001) were provided by the EGM96 global geopotential model (GGM), which itself was derived from a combination of satellite tracking data and terrestrial gravity and terrain data available in 1996 (Lemoine et al., 1998). Since then, the CHAMP (Challenging Mini-satellite Payload; Reigber et al., 1999) and GRACE (Gravity Recovery and Climate Experiment; Tapley et al., 2004a; 2004b) dedicated satellite gravimetry missions have been launched (on 15 
July 2000 and 17 March 2002, respectively). Overviews of the CHAMP, GRACE and the imminent GOCE (Gravity Field and Steady-State Ocean Circulation Explorer) mission concepts and aims are given by, e.g., Nerem et al. (1995), Balmino et al. (1999), Reigber et al. (1999), Rummel et al., (2002), Featherstone (2002), Chao (2003) and Tapley et al. (2004a; 2004b).

Since the launches of CHAMP and GRACE, over 20 new GGMs have been released. These are distributed freely by the International Centre for Global Earth Models (ICGEM) (http://icgem.gfz-potsdam.de/ICGEM/ICGEM.html) as ASCII files of fully normalised spherical harmonic coefficients of the Earth's external gravitational potential. Various other gravity-field-related quantities can be computed from these coefficients, such as gravity anomalies, quasigeoid heights and vertical deflections. [The subtle differences between the geoid and quasigeoid are outlined in Sjöberg (1995), Rapp (1997), Featherstone and Kirby (1997), Featherstone and Kuhn (2006) and Tenzer et al. (2006)]. Importantly, CHAMP/GRACE-based gravity field models are much better in the long wavelengths than previous GGMs (see Figure 3 later), which relied on tracking satellites with a limited range of orbital inclinations (e.g., Featherstone, 2002).

Work is currently underway to produce a new Australian gravimetric quasigeoid model that will incorporate new CHAMP/GRACE-based GGMs, new satellite altimetry, new gravity and new terrain data, as well as using improved mathematical models and computational techniques (see Featherstone et al. (2007) for a status report). The release of this new Australian quasigeoid model is deliberately being delayed until mid2008, after the EGM07 GGM and DNSC07 satellite-altimeter-derived gravity anomalies are released, probably in early-2008. EGM07 is currently being computed by the US National Geospatial Imagery Agency (NGA) in conjunction with SGT Inc. as a replacement for EGM96, and will be the highest-ever spherical harmonic expansion of the Earth’s gravity field, being complete to degree and order 2160 ( 10 km spatial resolution). DNSC07 marine gravity anomalies will be based on EGM07 and use retracked multi-mission satellite radar altimetry, which will improve the gravity data in the notoriously problematic coastal zone (cf. Deng and Featherstone, 2006).

This deliberate delay will allow EGM07, DNSC07 and other datasets to be tested in the Australian context so as to ensure better longevity of the new gravimetric quasigeoid model. The new model will also be fitted to GPS-levelling data at key Australian Height Datum (AHD) benchmarks across Australia using cross-validated least- 
squares collocation (cf. Featherstone and Sproule, 2006). This is so as to give a more directly useable product, specifically for GPS heighting (cf. Featherstone, 1998). Meanwhile, it is informative to gauge what improvements the current GRACE-derived combined GGMs may make upon AUSGeoid98.

\section{THE AUGMENTATION METHOD AND ITS LIMITATIONS}

Hipkin (1996) computed the EDIN891 gravimetric geoid model of Britain from an earlier regional gravimetric geoid model simply by subtracting the degree-360 geoid expansion of the OSU86E GGM (Rapp and Cruz, 1986), then adding back the degree-360 geoid expansion of the OSU91A GGM (Rapp et al., 1991). In this paper, this procedure is termed augmentation of the regional gravimetric quasigeoid model by the GGM. As pointed out by Featherstone and Olliver (2001), this approach is theoretically incorrect because it violates the remove-compute-restore approach (cf. Sjöberg, 2006), as follows.

In the combined solution for the geoid or quasigeoid, a GGM is merged with terrestrial gravity and terrain data via some adaptation of Stokes's integral (see, e.g., Featherstone et al. (2007) for a conceptual overview). However, this is not a perfect shiftfiltering process when the Stokes integration is over a limited region, and spectral leakage occurs among high and low frequencies (Vaníček and Featherstone, 1998). Therefore, and strictly, the same spherical harmonic degree and order of the same GGM must be subtracted (remove step) from the terrestrial gravity data before Stokes integration (compute step) as is added back later (restore step). If not, spurious long-wavelength errors result from the inconsistent use of different GGMs due to the spectral leakage problem. A more rigorous combination procedure is proposed by Sjöberg and Featherstone (2004), but this is not used here for reasons of convenience.

It is extremely difficult to quantify the error that the augmentation used here may generate, because numerous factors can contribute, such as the relative quality of the GGM and terrestrial gravity data added, the integration radius, etc. (Sjöberg and Featherstone, 2004). However, a crude guestimate is of the order of $20 \mathrm{~cm}$, which is deduced from the standard deviation (STD) of the difference between two GGMs (see Table 1, later).

Nevertheless, it is still informative to see if such augmentation of an existing regional gravimetric quasigeoid model can make any improvement in the Australian context. It must be stressed that this is only an experiment designed to give some approxi- 
mate idea of likely future improvements from GRACE (cf. Featherstone, 2002). As such, these augmented AUSGeoid models are not official product releases, and users should continue to use AUSGeoid98 until the official release of the new model that uses all new datasets in a rigorous combined solution (in mid-2008). AUSGeoid98 and associated software can be downloaded free-of-charge from: http://www.ga.gov.au/geodesy/ausgeoid/.

Two recently released GRACE-based combined (i.e., with global terrestrial data; see Featherstone, 2002) GGMs will be used in these experiments: GGM02C (Tapley et al., 2005) and EIGEN-GL04C (Förste et al., 2007). GGM02C was produced at the Centre for Space Research (CSR) at the University of Texas at Austin, USA, and is available complete to spherical harmonic degree and order 200 ( 100 km spatial resolution). EIGEN-GL04C was produced at the GeoForschungZentrum (GFZ) Potsdam, Germany, and is available complete to spherical harmonic degree and order 360 ( 55 km spatial resolution). Both models were downloaded free of charge from the ICGEM website (http://icgem.gfz-potsdam.de/ICGEM/ICGEM.html).

An in-house computer program, harmonics . $f$, which is a modified version of Rapp’s (1982) FORTRAN77 code, was used to evaluate EGM96, GGM02C and EIGEN-GL04C quasigeoid undulations from spherical harmonic synthesis on exactly the same 2-arc-minute by 2-arc-minute grid as used for AUSGeoid98 (cf. Featherstone et al., 2001). The main modification to harmonics . $f$ is the addition of Holmes and Featherstone's (2002) recursion routines, which significantly accelerate the computation speed. Note that GGM coefficients directly give quasigeoid undulations; additional computations are needed if the geoid is desired (Rapp, 1997; also see Sjöberg, 1995; Featherstone and Kirby, 1997; Featherstone and Kuhn, 2006; Tenzer et al., 2007). EGM96 quasigeoid heights were evaluated complete to degrees 200 and 360, GGM02C to 200 and EIGEN-GL04C to 360.

The augmentation (i.e., remove-replace) methodology is then rather straightforward. To augment AUSGeoid98 by GGM02C, the degree-200 EGM96 quasigeoid grid was subtracted (remove step) from the AUSGeoid98 grid, and then the degree-200 GGM02C quasigeoid grid subsequently added (replace step). Likewise, to augment by EIGEN-GL04C, degree-360 EGM96 was removed from AUSGeoid98, then replaced with degree-360 EIGEN-GL04C. The resulting augmented regional gravimetric quasigeoid models are respectively called AG98+GGM02C and AG98+GL04C. They are 
both on the same two-arc-minute grid as AUSGeoid98 and likewise refer to the GRS80 ellipsoid (Moritz, 1980).

\section{RESULTS, ASSESSMENTS AND DISCUSSION}

\section{Differences among GGMs}

First, it is informative to see how GGM02C and EIGEN-GL04C differ from EGM96 over the AUSGeoid98 computation area. In Figures 1 and 2, the main differences occur in the long and medium wavelengths, which is expected because of the improved lowfrequency gravity field information available from GRACE (Figure 3). However, the treatment of the terrestrial gravity data used in the GGM02C and EIGEN-GL04C combined GGMs also comes into play, also affecting the medium wavelengths. The more detail in Figure 2 is because of the different spatial resolution of the GGMs.

The largest differences (up to $2 \mathrm{~m}$ ) in Figures 1 and 2 occur near Indonesia, where the gravity field is very variable due to the subduction of the Australian plate beneath the Asian plate (e.g., Hillis and Müller, 2003). There is also a large difference ( 1 $\mathrm{m}$ ) in the Gulf of Carpentaria (centred at $\sim 12^{\circ} \mathrm{S}, \sim 140^{\circ} \mathrm{E}$ ), but the exact cause of this remains unknown at present. It is possible that the satellite altimeter data in this shallow sea, where tides are poorly modelled, have contaminated the GGMs. Over mainland Australia, the differences in Figures 1 and 2 are around $25 \mathrm{~cm}$.

The statistics of these differences, as well as differences from AUSGeoid98, are summarised in Table 1. While these values are biased by the large differences discussed above, it is important to show the whole picture because there are AUSGeoid98 users in marine areas, and there may even be some users in Indonesia. From the STDs in Table 1, the GRACE-based GGMs contribute around $20 \mathrm{~cm}$ differences from EGM96. This reflects the use of GRACE data, as well as the different treatment of the terrestrial gravity data (cf. Lemoine et al., 1998; Tapley et al., 2005; Förste et al., 2007). The STD of the differences between AUSGeoid98 and the various GGMs are around 40-50 cm, which shows the contribution of Australian gravity and terrain data to the GGMs. 


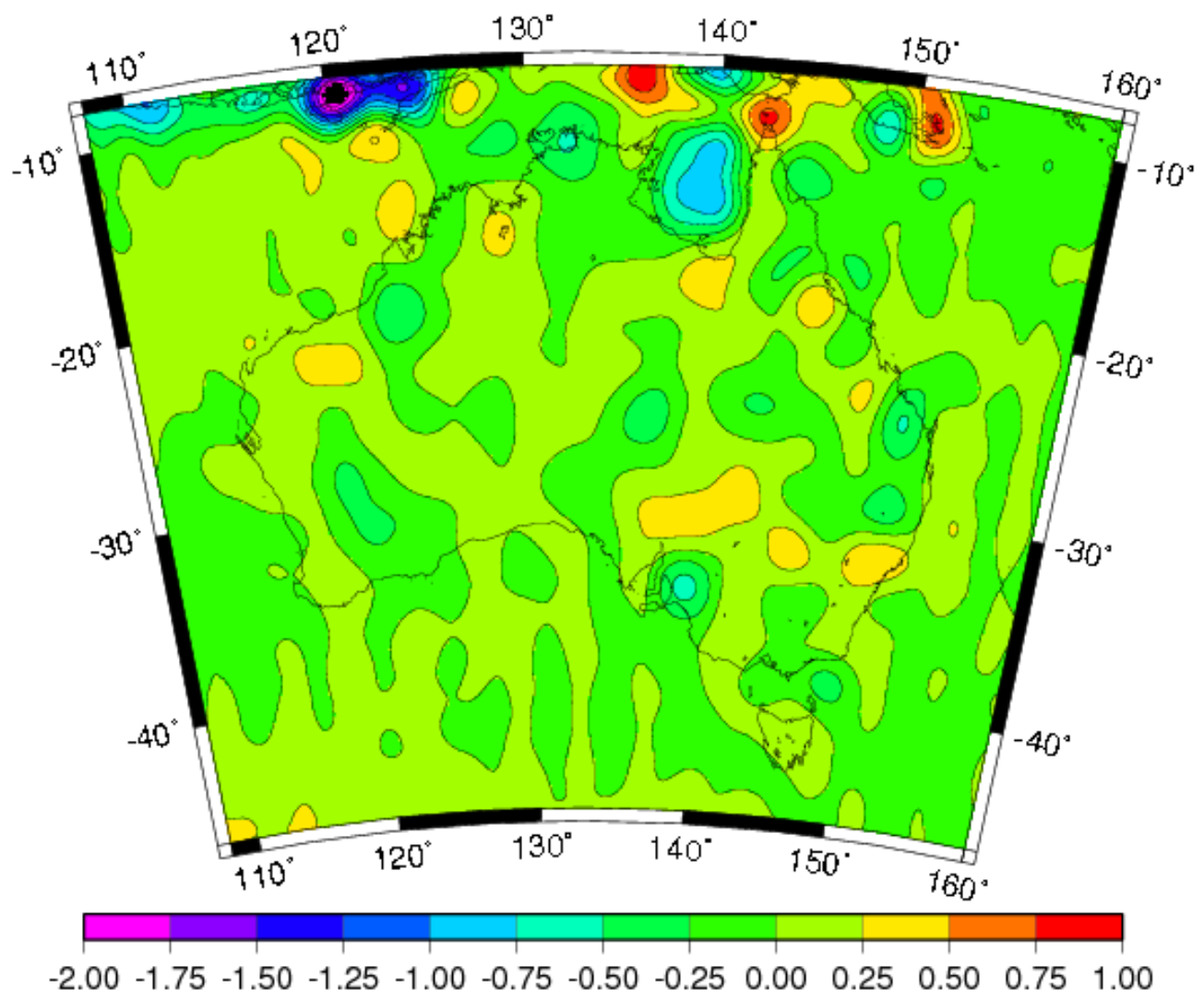

Figure 1 Differences between EGM96 and GGM02C quasigeoid heights to degree 200 ( 100 km resolution) over the AUSGeoid98 area (Units in metres; Lambert projection).

This is identical to the differences between AUSGeoid98 and AG98+GGM02C.

\begin{tabular}{|l|r|c|c|c|c|}
\hline \multicolumn{1}{|c|}{ GGM difference } & Degree & Max & Min & Mean & STD \\
\hline EGM96 minus GGM02C & 200 & +0.944 & -2.292 & -0.001 & \pm 0.207 \\
\hline EGM96 minus EIGEN-GL04C & 360 & +1.804 & -2.395 & -0.002 & \pm 0.231 \\
\hline AUSGeoid98 minus EGM96 & 200 & +4.743 & -11.000 & -0.005 & \pm 0.505 \\
\hline AUSGeoid98 minus EGM96 & 360 & +3.484 & -11.444 & -0.005 & \pm 0.411 \\
\hline AUSGeoid98 minus GGM02C & 200 & +4.158 & -10.921 & -0.006 & \pm 0.552 \\
\hline AUSGeoid98 minus EIGEN-GL04C & 360 & +2.597 & -10.968 & -0.005 & \pm 0.468 \\
\hline
\end{tabular}

Table 1 Descriptive statistics of the differences among EGM96, GGM02C, EIGENGL04C and AUSGeoid98 quasigeoid heights (Units in metres; 1,781,101 points) 


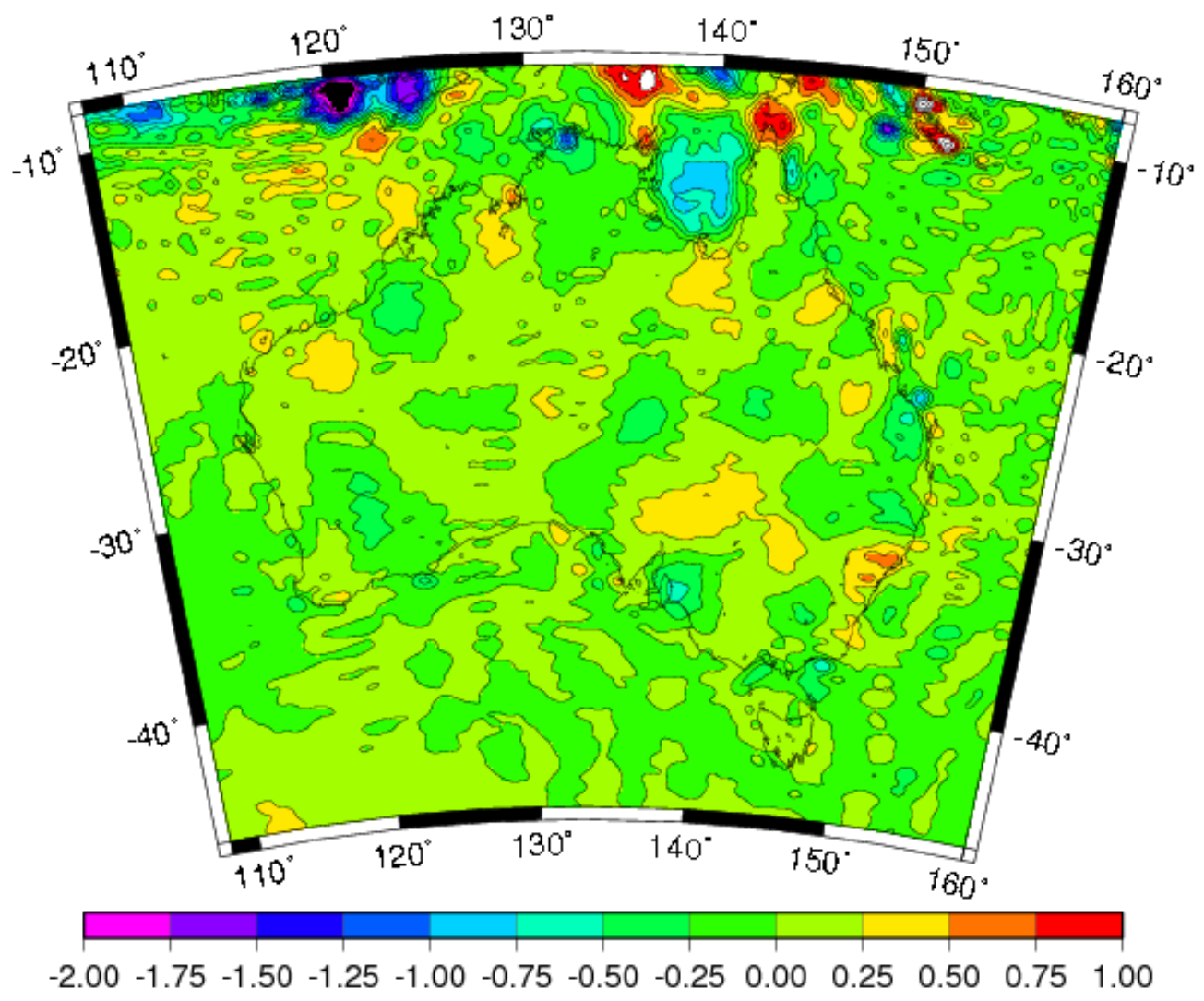

Figure 2 Differences between EGM96 and EIGEN-GL04C quasigeoid heights to degree 360 ( 55 km resolution) over the AUSGeoid98 area (Units in metres; Lambert projection). This is identical to the differences between AUSGeoid98 and AG98+GL04C.

\section{Comparisons with GPS-levelling}

Following, e.g., Featherstone and Guo (2001) and Amos and Featherstone (2003), the AG98+GGM02C and AG98+GL04C augmented quasigeoid models were compared with GPS-levelling data on the AHD. Comparing a quasigeoid with GPS-levelling on the AHD is consistent because the AHD uses a normal-orthometric height system (Featherstone and Kuhn, 2006). This comparison was extended to include the AUSGeoid98, EGM96, GGM02C and EIGEN-GL04C quasigeoid models. The geoid_abs_tester.f and geoid_rel_tester.f FORTRAN77 software (Featherstone, 2001) was used in both the absolute (single-point) and relative (baseline-bybaseline) modes (Tables 2 and 3, respectively). 


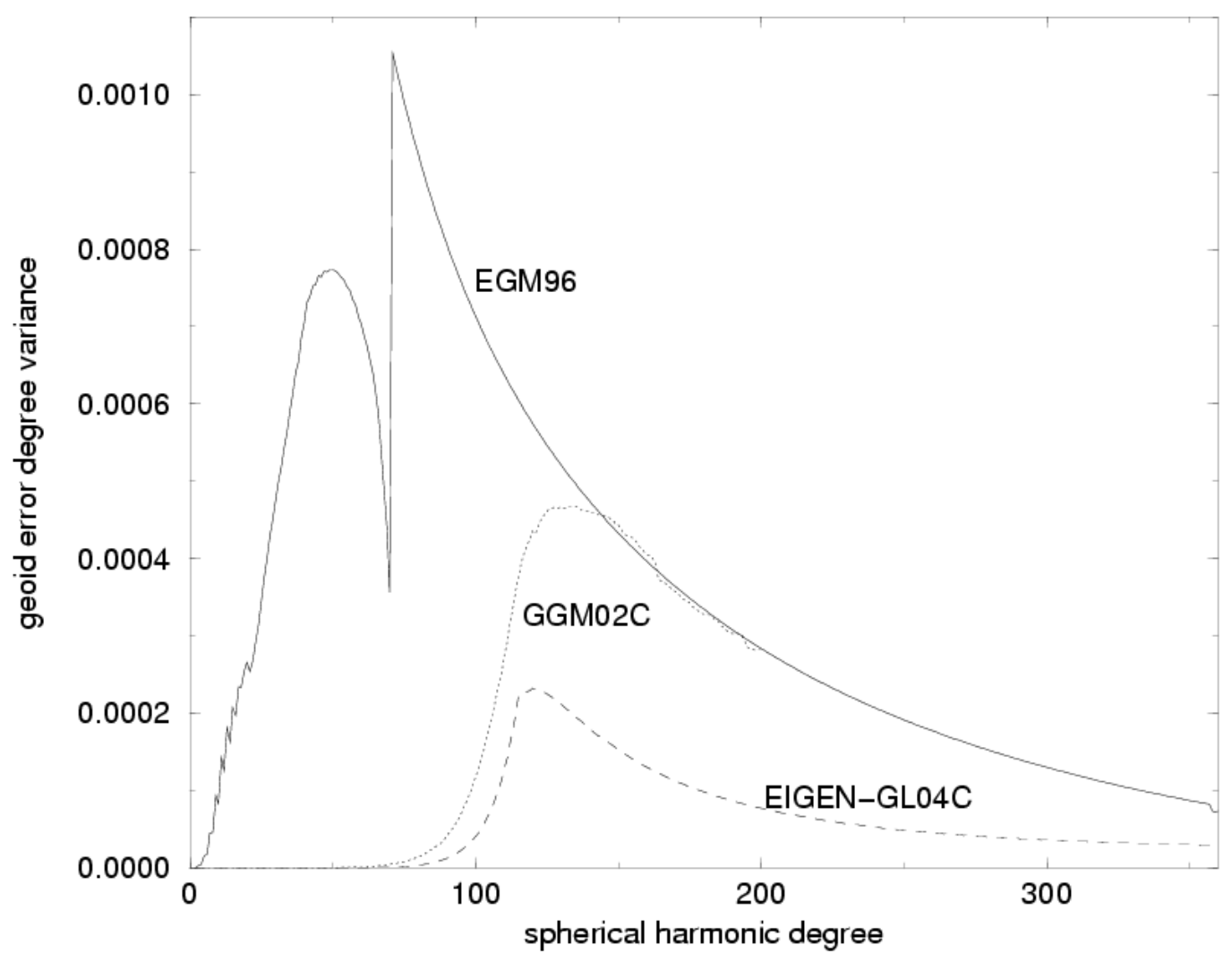

Figure 3 Error degree variance (spectral power of the error) of quasigeoid heights for EGM96, GGM02C and EIGEN-GL04C, showing the reduced low-frequency errors in the GRACE-based GGMs (Units in metres-squared).

This comparison uses the newer 254-point co-located GPS-AHD dataset provided by Geoscience Australia (cf. Featherstone and Sproule, 2006; Soltanpour et al., 2006; see Figure 4). It is acknowledged that this comparison is not conclusive because of distortions in the AHD (Featherstone, 2004; 2006; 2007; Featherstone and Kuhn, 2006), but the STDs in Table 2 give some indication that the GGM02C GRACE-based GGM can make some small ( $\sim \mathrm{cm})$ improvements to AUSGeoid98 for single-point GPS heighting (i.e., in the absolute sense). This will be improved much further, by 15 cm or more in STD, when cross-validated least-squares collocation is used to fit the quasigeoid model to the AHD (cf. Featherstone and Sproule, 2006). 


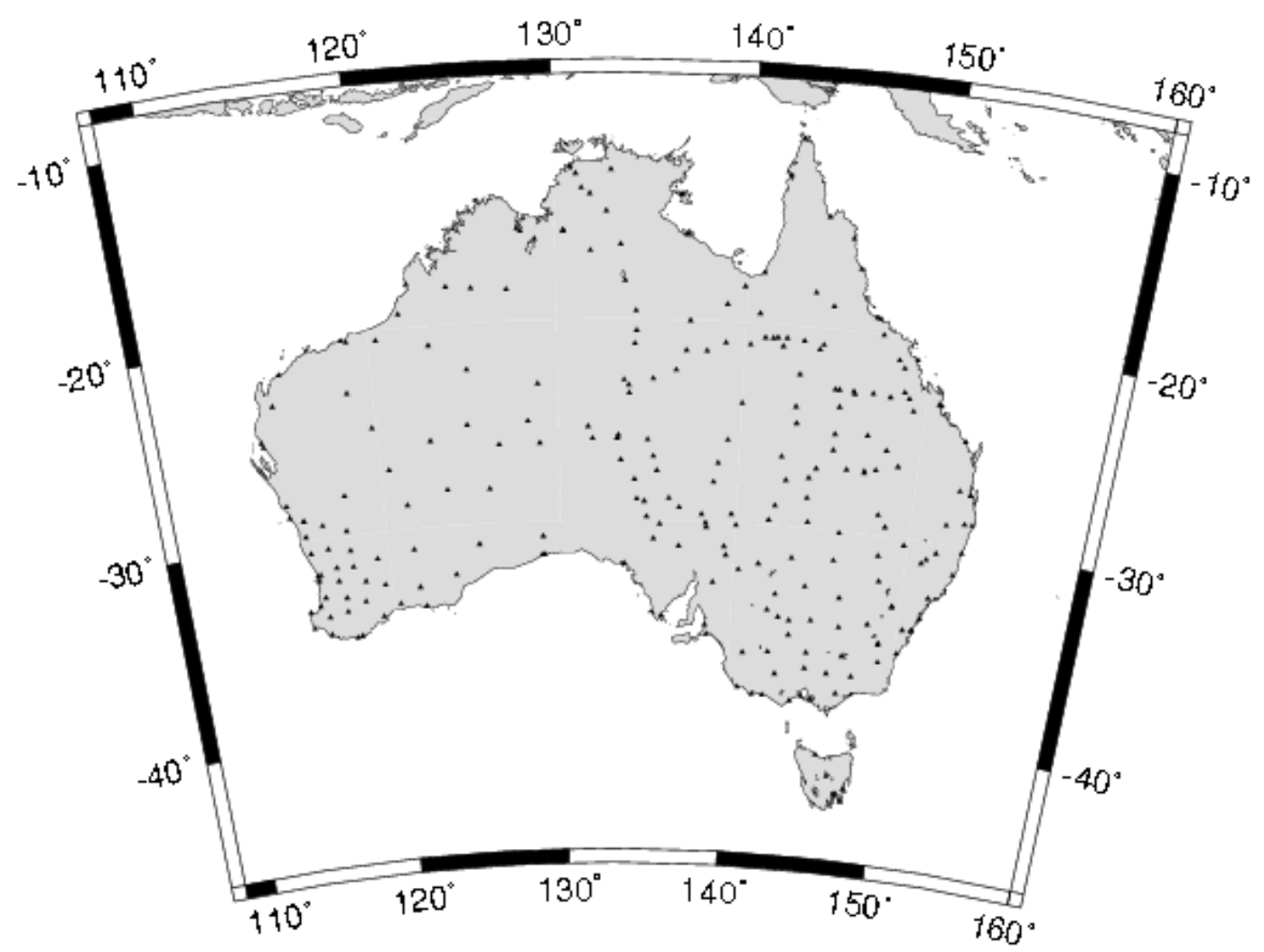

Figure 4 Coverage of the 254 GPS-levelling points (Lambert projection).

\begin{tabular}{|l|r|c|c|c|c|}
\hline \multicolumn{1}{|c|}{ Quasigeoid } & Degree & Max & Min & Mean & STD \\
\hline EGM96 & 200 & +1.093 & -1.299 & -0.026 & \pm 0.446 \\
\hline EGM96 & 360 & +0.894 & -0.961 & +0.009 & \pm 0.334 \\
\hline GGM02C & 200 & +0.950 & -1.318 & +0.007 & \pm 0.415 \\
\hline EIGEN-GL04C & 360 & +0.789 & -0.653 & +0.059 & \pm 0.293 \\
\hline AUSGeoid98 & N/A & +0.865 & -0.721 & +0.077 & \pm 0.284 \\
\hline AG98+GGM02C & N/A & +1.066 & -0.671 & +0.110 & \pm 0.268 \\
\hline AG98+GL04C & N/A & +1.079 & -0.667 & +0.127 & \pm 0.286 \\
\hline
\end{tabular}

Table 2 Descriptive statistics of the absolute differences between quasigeoid models and 254 co-located GPS-AHD points (Units in metres) 


\begin{tabular}{|l|r|c|c|c|c|c|}
\hline \multicolumn{1}{|c|}{ Quasigeoid } & Degree & Max & Min & Mean & STD & ppm \\
\hline EGM96 & 200 & +2.382 & -2.391 & +0.091 & \pm 0.625 & 2.45 \\
\hline EGM96 & 360 & +1.855 & -1.665 & +0.076 & \pm 0.467 & 2.31 \\
\hline GGM02C & 200 & +2.213 & -2.268 & +0.090 & \pm 0.581 & 2.41 \\
\hline EIGEN-GL04C & 360 & +1.442 & -1.390 & +0.066 & \pm 0.410 & 2.27 \\
\hline AUSGeoid98 & N/A & +1.409 & -1.587 & +0.008 & \pm 0.402 & 2.24 \\
\hline AG98+GGM02C & N/A & +1.737 & -1.589 & +0.007 & \pm 0.380 & 2.23 \\
\hline AG98+GL04C & N/A & +1.747 & -1.578 & -0.001 & \pm 0.406 & 2.25 \\
\hline
\end{tabular}

Table 3 Descriptive statistics of the relative differences between quasigeoid models over the 32,131 possible baselines between and 254 GPS-AHD points (Units in metres)

Another observation from Tables 2 and 3 is that AUSGeoid98 provides a better fit to the AHD in absolute and relative senses than all the GGMs tested. This is expected because of the limited spatial resolution of the GGMs (omission error) versus the higher resolution of AUSGeoid98. The effect of the omission error can be seen when comparing the degree-200 and degree-360 expansions of EGM96, where the higher the degree of expansion gives a better fit to the GPS-levelling. However, the commission errors (errors in the coefficients) of GGM02C and EIGEN-GL04C are smaller than EGM96 (for the same degrees), showing the improvement coming from GRACE (cf. Gunter et al., 2006; also see Figure 3).

\section{Comparisons with vertical deflections}

An arguably better validation of a regional gravimetric quasigeoid model and GGM is through comparison with astrogeodetically observed vertical deflections (Jekeli, 1999; Featherstone, 2006; 2007; Featherstone and Morgan, 2007), which are more independent and better at sensing the high-frequency components of the gravity field. The validation presented here uses a dataset of 1080 vertical deflections (Figure 5), extending on that used in Featherstone (2006) by including additional points in Western Australia provided by Landgate (Featherstone and Morgan, 2007) and SGT Inc. (see Featherstone, 2007). 


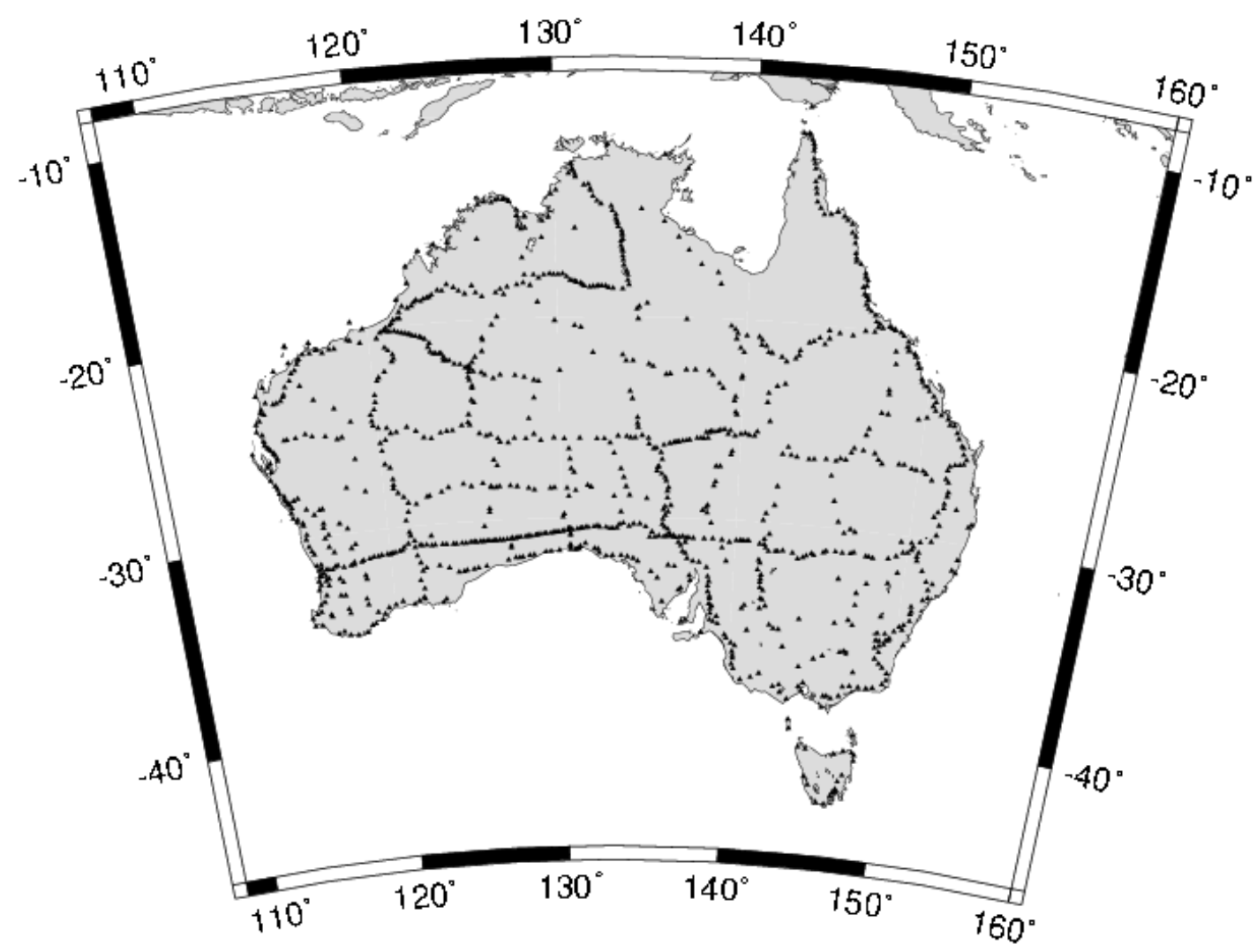

Figure 5. Coverage of the 1080 astrogeodetically observed vertical deflections [Lambert projection]

This evaluation required the development of some new software. Whilst har monics . $f$ can determine vertical deflections directly from the fully normalised spherical harmonic coefficients of any GGM, new code was needed to test the AG98+GGM02C and AG98+GL04C augmented models. This code determined the east-west and north-south vertical deflections from the horizontal quasigeoid gradients using the equations in Featherstone and Rüeger (2000); also see Featherstone and Morgan (2007).

The resulting grids of vertical deflections were then compared to the astrogeodetically observed vertical deflections using geoid_abs_tester.f (Featherstone, 2001). Tables 4 and 5 show the descriptive statistics of the differences between the astrogeodetically observed vertical deflections and the vertical deflections derived from the various quasigeoid models, after outlier rejection in the east-west and north-south 
components based on the three-sigma test, which is permitted because the differences are near-normally distributed (cf. Featherstone and Morgan, 2007).

In the outlier rejection, if one component was an outlier, then it was rejected for the other component. This proved to be rather robust in that most of the outliers were common among models and common among deflection components. It should be noted that a limitation of this analysis is that curvature and torsion of the plumbline have been ignored, as well as the quasigeoid not describing an equipotential surface (cf. Featherstone and Morgan, 2007). However, these effects are probably small in Australia, especially when taking into account the quality of the astrogeodetic deflections that were observed over 40 years ago (Featherstone and Rüeger, 2000; Featherstone, 2006; 2007; Featherstone and Morgan, 2007).

\begin{tabular}{|l|r|r|r|r|r|r|}
\hline \multicolumn{1}{|c|}{ Quasigeoid } & Degree & Max & Min & Mean & STD & $\begin{array}{r}\text { Rejected } \\
\text { outliers }\end{array}$ \\
\hline EGM96 & 200 & 7.73 & -8.15 & -0.18 & \pm 1.79 & 15 \\
\hline EGM96 & 360 & 6.21 & -7.31 & -0.19 & \pm 1.54 & 19 \\
\hline GGM02C & 200 & 6.99 & -6.90 & -0.18 & \pm 1.64 & 14 \\
\hline EIGEN-GL04C & 360 & 6.15 & -6.28 & -0.18 & \pm 1.46 & 21 \\
\hline AUSGeoid98 & N/A & 3.28 & -3.91 & -0.25 & \pm 0.84 & 26 \\
\hline AG98+GGM02C & N/A & 3.26 & -3.87 & -0.24 & \pm 0.82 & 28 \\
\hline AG98+GL04C & N/A & 3.28 & -4.02 & -0.26 & \pm 0.83 & 25 \\
\hline
\end{tabular}

Table 4 Descriptive statistics of the differences between quasigeoid-derived east-west vertical deflections and astrogeodetic east-west vertical deflections (Units in arcseconds)

From the results in Tables 4 and 5, the augmented models (AG98+GGM02C and AG98+GL04C) make virtually no difference to the vertical deflections. This is to be expected because vertical deflections have most of their power in the high frequencies, so are relatively insensitive to the change in GGM. [Another factor is the quality of the astrogeodetic vertical deflections.] Instead, the deflections are mainly influenced by the local gravity and terrain data, so reflect the residual quasigeoid computed for AUSGe- 
oid98. This is why the statistics in Tables 4 and 5 are virtually identical for all of AUSGeoid98, AG98+GGM02C and AG98+GL04C.

\begin{tabular}{|l|r|r|r|r|r|r|}
\hline \multicolumn{1}{|c|}{ Quasigeoid } & Degree & Max & Min & Mean & STD & $\begin{array}{r}\text { Rejected } \\
\text { outliers }\end{array}$ \\
\hline EGM96 & 200 & 9.61 & -10.69 & -0.15 & \pm 2.71 & 15 \\
\hline EGM96 & 360 & 9.45 & -9.33 & -0.08 & \pm 2.19 & 19 \\
\hline GGM02C & 200 & 9.45 & -9.99 & -0.12 & \pm 2.66 & 14 \\
\hline EIGEN-GL04C & 360 & 9.76 & -9.47 & -0.10 & \pm 2.23 & 21 \\
\hline AUSGeoid98 & N/A & 3.76 & -3.62 & -0.14 & \pm 1.09 & 26 \\
\hline AG98+GGM02C & N/A & 3.77 & -3.59 & -0.14 & \pm 1.08 & 28 \\
\hline AG98+GL04C & N/A & 4.00 & -3.72 & -0.15 & \pm 1.12 & 25 \\
\hline
\end{tabular}

Table 5 Descriptive statistics of the absolute differences between quasigeoid-derived north-south vertical deflections and astrogeodetic north-south vertical deflections

(Units in arc-seconds)

\section{CONCLUSION AND DISCUSSION}

The experiments reported here on augmenting AUSGeoid98 with two recently released GRACE-based combined GGMs have proven somewhat inconclusive in that they do not provide any significant improvement over AUSGeoid98 alone when compared to GPSlevelling and vertical deflections.

From Figure 3, however, the GRACE-based models do make significant improvements on EGM96 in the low frequencies in a global sense, but this is not manifested in comparisons with Australian GPS-levelling and astrogeodetic vertical deflection data. A limitation is the distortions in the AHD and the vintage of the astrogeodetic vertical deflections. On the other hand, the spatial differences between AUSGeoid98 and the two augmented models (Figures 1 and 2) show $\sim 25 \mathrm{~cm}$ differences in most places, which indicates that the spatial sampling of GPS-levelling and astrogeodetic vertical deflections (Figures 4 and 5) does not capture these changes properly.

Another limiting factor is that the GGM02C and EIGEN-GL04C combined GGMs use largely the same terrestrial gravity data as EGM96, which is also largely the 
same terrestrial gravity data that was used in AUSGeoid98. Therefore, they are highly correlated in the medium frequencies, so the results merely reflect the effect of the same data. If these data are in error, then the improvements from GRACE will be obscured. As such, it will be important to carefully look at the use of filters in the production of the next AUSGeoid (cf. Kern et al., 2003; Featherstone 2003).

Finally, these experimental results should not be seen as a definitive statement that the inclusion of GRACE data will not make an improvement over AUSGeoid98. This is because the remove-replace augmentation procedure used here is theoretically inexact, and thus might not give a complete picture.

\section{ACKNOWLEDGEMENTS}

I would like to thank the Australian Research Council (ARC) for my Australian Professorial Fellowship through grant DP0663020, Geoscience Australia, Landgate and SGT Inc., USA, for providing GPS-levelling and vertical deflection data, the International Centre for Global Earth Models (ICGEM) for making GGMs readily accessible, and the creators of GGMs for freely providing their coefficients. I would also like to thank the reviewers and editors for their comments on this manuscript. The figures in this manuscript were produced with the publicdomain Generic Mapping Tools (Wessel and Smith (1998) http://gmt.soest.hawaii.edu/). This is The Institute for Geoscience Research (TIGeR) publication number 75.

\section{REFERENCES}

Amos, M.J. and Featherstone, W.E. (2003) Preparations for a new gravimetric geoid model of New Zealand, and some preliminary results, New Zealand Surveyor, vol. 293, pp. 9-20.

Balmino, G., Perosanz, F., Rummel, R., Sneeuw, N. and Sünkel, H. (1999) CHAMP, GRACE and GOCE: mission concepts and simulations, Bolletino di Geofisica Teoria ed Applicata, vol. 40, no. 4, pp. 555-563.

Chao, B.F. (2003) Geodesy is not just for static measurements any more, EOS - Transactions of the American Geophysical Union, vol. 84, pp. 145-150, doi: 10.1029/2003EO160001.

Deng, X.L. and Featherstone, W.E. (2006) A coastal retracking system for satellite radar altimeter waveforms: application to ERS-2 around Australia, Journal of Geophysical Research Oceans, vol. 111, article C06012, doi: 10.1029/2005JC003039.

Featherstone, W.E. (1998) Do we need a gravimetric geoid or a model of the base of the Australian Height Datum to transform GPS heights? The Australian Surveyor, vol. 43, no. 4, pp. 273-280.

Featherstone, W.E. (2001) Absolute and relative testing of gravimetric geoid models using Global Positioning System and orthometric height data, Computers \& Geosciences, vol. 27, no. 7, pp. 807-814, doi: 10.1016/S0098-3004(00)00169-2. 
Featherstone, W.E. (2002) Expected contributions of dedicated satellite gravity field missions to regional geoid determination with some examples from Australia, Journal of Geospatial Engineering, vol. 4, no. 1, pp. 1-19.

Featherstone, W.E (2003) Band-limited kernel modifications for regional geoid determination based on dedicated satellite gravity field missions, in: Tziavos, I.N. (ed) Gravity and Geoid 2002, Department of Surveying and Geodesy, Aristotle University of Thessaloniki, Greece, pp. 341-346.

Featherstone, W.E. (2004) Evidence of a north-south trend between AUSGeoid98 and the AHD in southwest Australia, Survey Review, vol. 37, no. 291, pp. 334-343.

Featherstone, W.E. (2006) Yet more evidence for a north-south slope in the AHD, Journal of Spatial Science, vol. 51, no. 2, pp. 1-6.

Featherstone, W.E. (2007) Corrigendum to "Yet more evidence for a north-south slope in the Australian Height Datum”, Journal of Spatial Science, vol. 52, no. 1, pp. 65-68.

Featherstone, W.E. and Kirby, J.F. (1998) Estimates of the separation between the geoid and quasi-geoid over Australia, Geomatics Research Australasia, vol. 68, pp. 75-86.

Featherstone, W.E. and Rüeger, J.M. (2000) The importance of using deviations of the vertical in the reduction of terrestrial survey data to a geocentric datum, The Trans-Tasman Surveyor, vol. 1, no. 3, pp. 46-61 [Erratum in The Australian Surveyor, vol. 47, no. 1, pp. 7]

Featherstone, W.E. and Guo, W. (2001) Evaluations of the precision of AUSGeoid98 versus AUSgeoid93 using GPS and Australian Height Datum data, Geomatics Research Australasia, vol. 74, pp. 75-102.

Featherstone, W.E. and Olliver, J.G. (2001) A review of geoid models over the British Isles: progress and proposals, Survey Review, vol. 36, no. 280, pp. 78-100.

Featherstone, W.E. and Kuhn, M. (2006) Height systems and vertical datums: a review in the Australian context, Journal of Spatial Science, vol. 51, no. 1, pp. 21-42

Featherstone, W.E. and Sproule, D.M. (2006) Fitting AUSGeoid98 to the Australian Height Datum using GPS data and least squares collocation: application of a cross-validation technique, Survey Review, vol. 38, no. 301, pp. 573-582.

Featherstone, W.E. and Morgan, L. (2007) Validation of the AUSGeoid98 model in Western Australia using historic astrogeodetically observed deviations of the vertical, Journal of the Royal Society of Western Australia, vol. 90, no. 3 (in press)

Featherstone, W.E., Kirby, J.F., Kearsley, A.H.W., Gilliland, J.R., Johnston, G.M., Steed, J., Forsberg, R., and Sideris, M.G. (2001) The AUSGeoid98 geoid model of Australia: data treatment, computations and comparisons with GPS-levelling data, Journal of Geodesy, vol. 75, no. 5-6, pp. 313-330, doi: 10.1007/s001900100177.

Featherstone, W.E., Claessens, S.J., Kuhn, M., Kirby, J.F., Sproule, D.M., Darbeheshti, N., and Awange, J.L. (2007) Progress towards the new Australian geoid-type model as a replacement for AUSGeoid98, Proceedings of SSC 2007, Hobart, Australia, May 2007 [CD-ROM]

Förste, C., Flechtner, F., Schmidt, R., Meyer, U., Stubenvoll, R., Barthelmes, F., König, R., Neumayer, K.H., Rothacher, M., Reigber, C., Biancale, R., Bruinsma, S., Lemoine, J.-M., and Raimondo, J.C. (2007) A New high resolution global gravity field model derived from combination of GRACE and CHAMP mission and altimetry/gravimetry surface gravity data, Journal of Geodesy (submitted)

Gunter, B, Ries, J., Bettadpur, S. and Tapley, B.D. (2006) A simulation study of the errors of omission and commission for GRACE RL01 gravity fields, Journal of Geodesy, vol. 80, no. 4, pp. 341-351, doi: 10.1007/s00190-006-0083-3. 
Hillis, R.R. and Müller, R.D., eds, (2003) The Evolution and Dynamics of the Australian Plate, Geological Society of Australia Special Publication 22 and Geological Society of America Special Paper 372, 432 pp.

Hipkin, R.G. (1996) Geoid models for Great Britain and the North Sea., International Geoid Service Bulletin, no. 4, pp. 131-135.

Holmes, S.A. and Featherstone, W.E. (2002) A generalised approach to the Clenshaw summation and the recursive computation of very-high degree and order normalised associated Legendre functions, Journal of Geodesy, vol. 76, no. 5, pp. 279-299, DOI: 10.1007/s00190002-0216-2.

Jekeli, C. (1999) An analysis of vertical deflections derived from high-degree spherical harmonic models, Journal of Geodesy, vol. 73, no. 1, pp. 10-22, doi: 10.1007/s001900050213

Kern, M., Schwarz, K-P. and Sneeuw, N. (2003) A study on the combination of satellite, airborne, and terrestrial gravity data, Journal of Geodesy, vol. 77, no. 3-4, pp. 217-225, doi: 10.1007/s00190-003-0313-x

Lemoine, F.G., Kenyon, S.C., Factor, J.K., Trimmer, R.G., Pavlis, N.K., Chinn, D.S., Cox, C.M., Klosko, S.M., Luthcke, S.B., Torrence, M.H., Wang, Y.M., Williamson, R.G., Pavlis, E.C., Rapp, R.H. and Olson, T.R. (1998) The development of the joint NASA GSFC and the National Imagery and Mapping Agency (NIMA) geopotential model EGM96, NASA/TP1998-206861, National Aeronautics and Space Administration, Greenbelt, USA, 575 pp.

Moritz, H. (1980) Geodetic reference system 1980, Bulletin Géodésique, vol. 54, no. 4, pp. 395405.

Nerem, R.S., Jekeli, C. and Kaula, W.M. (1995) Gravity field determination and characteristics: retrospective and prospective, Journal of Geophysical Research - Solid Earth, vol. 100, no. B8, pp. 15053-15074.

Rapp, R.H. (1982) A FORTRAN program for the computation of gravimetric quantities from high-degree spherical harmonic expansions, Report 334, Department of Geodetic Science and Surveying, Ohio State University, Columbus, USA.

Rapp, R.H. (1997) Use of potential coefficient models for geoid undulation determinations using a spherical harmonic representation of the height anomaly/geoid undulation difference, Journal of Geodesy, vol. 71, no. 4, pp 282-289.

Rapp, R.H. and Cruz, J.Y. (1986) Spherical harmonic expansions of the Earth's gravitational potential to degree 360 using 30' mean anomalies, Report 376, Department of Geodetic Science and Surveying, Ohio State University, Columbus, USA.

Rapp, R.H., Wang, Y.M. and Pavlis, N.K., (1991) The Ohio State 1991 geopotential and sea surface topography harmonic coefficient models, Report 410, Department of Geodetic Science and Surveying, Ohio State University, Columbus, USA.

Reigber, C., Schwintzer, P. and Lühr, H. (1999) CHAMP geopotential mission, Bulletin Geofisica Theoretica e Applicata, vol. 40, no. 4, pp. 285-289.

Rummel, R., Balmino, G., Johannessen, J., Visser, P., and Woodworth, P. (2002) Dedicated gravity field missions - principles and aims, Journal of Geodynamics, vol. 33, no. 1, pp. 320, doi: 10.1016/S0264-3707(01)00050-3.

Sjöberg, L.E. (1995) On the quasigeoid to geoid separation, manuscripta geodaetica, vol. 20, no. 3, pp. 182-192.

Sjöberg, L.E. (2006) A discussion on the approximations made in the practical implementation of the remove-compute-restore technique in regional geoid modelling, Journal of Geodesy, vol. 78, nos. 11-12, pp. 645-653, doi: 10.1007/s00190-004-0430-1. 
Sjöberg, L.E. and Featherstone, W.E. (2004) Two-step procedures for hybrid geoid modelling, Journal of Geodesy, vol. 78, no. 1-2, pp. 66-75, doi: 10.1007/s00190-003-0367-9.

Soltanpour, A., Nahavandchi, H. and Featherstone, W.E. (2006) The use of second-generation wavelets to combine a gravimetric geoid model with GPS-levelling data, Journal of Geodesy, vol. 80, no. 2, pp. 82-93, doi: 10.1007/s00190-006-0033-0.

Tapley, B.D., Bettadpur, S., Watkins, M., and Reigber, C. (2004a) The Gravity Recovery and Climate Experiment: mission overview and early results, Geophysical Research Letters, vol. 31, article L09607, doi:10.1029/2004GL019920.

Tapley, B.D., Bettadpur, S., Ries, J.C., Thompson, P.F., and Watkins, M.M. (2004b) GRACE measurements of mass variability in the Earth system, Science, vol. 305, no. 5683 pp. 503506, doi: 10.1126/science.1099192.

Tapley, B., Ries, J., Bettadpur, S., Chambers, D., Cheng, M., Condi, F., Gunter, B., Kang, Z., Nagel, P., Pastor, R., Pekker, T., Poole, S. and Wang, F. (2005) GGM02 - An improved Earth gravity field model from GRACE, Journal of Geodesy, vol. 79, no. 8, pp. 467-478, doi: 10.1007/s00190-005-0480-z.

Tenzer, R., Novák, P., Moore, P., Kuhn, M. and Vaníček, P. (2006) Explicit formula for the geoid-quasigeoid separation, Studia Geophysica et Geodaetica, vol. 50, no. 4, pp. 607-618, doi: 10.1007/s11200-006-0038-4

Vaníček, P. and Featherstone, W.E. (1998) Performance of three types of Stokes's kernel in the combined solution for the geoid, Journal of Geodesy, vol. 72, no. 12, pp. 684-697, doi: $10.1007 / \mathrm{s} 001900050209$.

Wessel, P. and Smith, W.H.F. (1998) New, improved version of Generic Mapping Tools released, EOS - Transactions of the American Geophysical Union, vol. 79, no. 47, pp. 579 